THURSDAY, APRIL 24, 1890.

\section{THE REVISED INSTRUCTIONS TO} INSPECTORS.

I AST year it was a matter of considerable complaint Code was presented to Parliament unaccompanied by the new instructions to inspectors, without which it could neither be satisfactorily interpreted nor adequately discussed. No such complaint can be made this year. The issue of the new Code, which promises to place elementary schools under what is practically a new system of regulations, has been followed within a few days by a revised edition of the instructions to inspectors, in which the changes are correspondingly large. Indeed, more than half of the document consists of new matter.

On the whole, the approbation which has greeted Mr. Kekewich's Code may be extended to the instructions by which it is explained. So far as we can see, there is no shuffling, no attempt to minimise or to alter the practical effect of the reforms which are conceded on paper in the Code.

The main alterations occur in those parts of the instructions which are to guide the inspector in awarding the Parliamentary grant under the new régime. It will be remembered that the system of payment on the results of individual examination disappears almost completely, and is replaced by a grant made up of three parts-a "principal grant" of $12 s$. $6 d$. or I $4 s$, , a grant of Is. $6 d$. or 2s. for discipline and organization, and a payment as before on results of examination in the so-called "additional subjects." The mode of examination to be adopted in future in the elementary subjects on which the "principal grant" depends is substantially that already in use for "class subjects." That is to say, there will be a collective examination by sample, a certain proportion of children out of each class being chosen at random for examination by the inspector, the teacher being always invited to add a few of his most forward scholars, so that the school may not be injured by any accident in the selection. Several alternative modes of selection are suggested, and the inspector is expressly asked to vary his method from time to time, rather than to adopt any uniform plan. Teachers and managers may hear the oral examination and see the papers, but they are to be warned that "it is not by studying past questions, nor by trying to forecast the kind of questions likely to be set hereafter, but by teaching the subject with good sense and thoroughness that the requirements of the Department will be best fulfilled, and the truest educational success achieved."

The higher "principal grant" is not to be awarded unless a high standard of proficiency is reached in all three elementary subjects. If the scholars do not reach the standard required for the lower " principal grant," the managers are to be warned that next year the grant may be discontinued; and, in all cases where the higher grant is not awarded, the points in which the school is deficient are to be clearly indicated to the managers.

These regulations, if wisely carried out, must be a great improvement on those under which the grant is at VOL. XLI.-NO. 1069. present assessed. The old barbarous system of bleeding a bad school to death by diminishing its grant below the minimum required for its efficient maintenance will be discontinued. In place of this a school, so long as it receives anything, will receive enough to enable it to be efficient if the teachers and managers are up to their work. If such a school fails to reach the required standard, though supplied with public aid on as liberal a scale as that on which multitudes of schools do contrive to be efficient, it will simply be removed from the list of grantearning schools. This is the rational course, if carried out in practice, but very much will depend on the inspector. It is sincerely to be hoped that the instructions will be carried out in such a way as to ensure that the "liberal grant now offered to comparatively humble schools shall serve as an aid and stimulus to improvement, and not as a pretext for remaining content with a low standard of duty."

With the disappearance of payment on individual results in the elementary subjects, the necessity for many of the minute regulations as to the exact meaning of a "pass" in each subject disappears also. But the necessity still remains for the inspector to keep in mind the standard of an individual pass for such purposes as that of the scholar requiring a "labour pass" either for half-time or whole-time exemption.

A few modifications are made in the instructions respecting the three elementary subjects. The justice of the oft-repeated complaints which have been made of the excessive time devoted to English grammar is recognized, not only in the altered regulations for English, but in a great reduction in the "spelling" requirements. As regards reading, it is suggested that a class of older scholars should be set to read a passage to themselves while another class is being examined, and then be questioned as to its matter. Writing will be partly tested by examination of school copy-books, not merely by a piece of writing executed during the anxious and nervous hours of the inspector's visit.

But the most important changes bearing on the school curriculum-indeed, perhaps, on the whole, the most important changes in the whole document-are those passages in which an attempt is made to link the instruction of the school to the life of the home. On the one hand, the co-operation of the parents is to be expressly invited; on the other hand, their special wants are to be more directly consulted. For example, it is pointed out that "in some good schools the aid of the parents has been successfully enlisted, and they have been urged to hear their children read aloud from a newspaper or from a book for a few minutes at home in every day. The amount of oral practice which any one child can obtain in a large class is obviously insufficient; and a little home exercise in reading aloud is often found to have an excellent effect." On the other hand, the elder girls are to be allowed to bring from home garments that want mending, and to repair them in school under the teachers' supervision-an arrangement which will "connect the school-work usefully with the every-day life of the scholars." There are other hints to a similar effect, as in the concluding paragraphs of the instructions, which enumerate the ways in which, besides conforming to the requirements of the Code, a school may seek "to render $\mathrm{C} \mathrm{C}$ 
service to the children who attend it and to their parents." Taken one by one, the suggestions may seem unimportant; collectively, however, they indicate a policy of taking the p.rents frankly into confidence, and so, if possible, of establishing a new link of interest between the parent and the school, besides the mere "cash-nexus" of the school pence, which are destined so soon to disappear.

Under the head of "class subjects" an explanation is given of the object of the great changes in Schedule II., which, we learn, have been introduced in order to allow of greater freedom to teachers of different tastes and capacities, and to localities of different industries and requirements. "One good teacher of geography may attach special value to physical facts and phenomena; another who lives in a manufacturing or maritime town prefers to make commercial and industrial geography and the interchange of productions the leading features of his lessons." The same standard is, so far as possible, to be kept in view, in estimating the teaching of all the various alternative courses; but, subject to this one consideration, complete freedom of choice and treatment is to be given to teachers and managers. "In sanctioning any modification of the printed schemes it will be necessary to have regard to the experience and qualifications of the teacher, and to any special opportunities afforded in the town or district for instruction by a skilled demonstrator, who visits several schools in succession, or who gives collective lessons at suitable centres."

The instructions further confirm the view we expressed when commenting on the Code, that the policy of the Department will be to encourage class teaching at the expense of specific subjects. "Those managers and teachers who desire to continue the object-lessons of the infant school in due order through all the lower standards, and so to lead up to the regular study of natural history or physics in the higher, will probably think it better to treat science as a class subject than to postpone specific instruction until the fifth standard."

The recognition of continuity, and the idea of the school course as a connected whole, strikes us as a new and valuable feature in the instructions. From the infant school the child is to be led on through a series of object-lessons to the scientific class-teaching of the upper school, and thence in some cases to specific instruction in the higher standards. But all this is but the beginning. "Teachers should not be satisfied unless the instruction in specific subjects awakens in the scholar a desire for further knowledge, and makes him willing to avail himself of such opportunities as are afforded locally by a Science Class, a Polytechnic Institute, a course of University Extension Lectures, a Free Library, or a Home-Reading Circle." All this is a truism, it may be said ; but it is unusual language for an official document, and carries us forward in imagination to the time, which must come sooner or later, when such fragmentary and scattered institutions as are here enumerated will take their proper place as parts of a great scheme of national education.

We fear that the realization of the aims of the Department may be materially impeded if a literal construction is to be placed on the clause providing that the same subject may not be taken both as a "class" and as a "specific" subject. Does this restriction merely mean that no child is to be presented in the same subject under both heads-an obviously reasonable stipulation-or that no children in a school may take as a specific subject any branch of study which is taken as a class subject by any other children in the school? If the latter is the case, we are informed that, in some cases at least, managers will find themselves seriously hampered.

Provision is made for the assistance of experts in the examination of scholars, in cases where the managers choose an "additional" subject with which neither the inspector nor his assistants are fully conversant. But unfortunately this assistance, which will be given by a colleague, on application to the chief inspector, will be confined to the framing of suitable questions, and marking the answers, and hence will be inapplicable to the case of oral examination, in which it is most wanted.

Those interested in manual instruction. will turn with interest to the thirty-fifth section, which lays down the duties of inspectors with respect to this newly recognized branch of instruction. It explains that the difficulty which has hitherto prevented the recognition of manual instruction as part of the ordinary course of instruction in a public elementary school has been removed by the alteration in the terms of Art. $12(f)$, though how such a change in Departmental regulations can alter the sense of an Act of Parliament we are left to conjecture. The instructions suggest such exercises as "modelling, the cutting, fixing, and inventing of paper patterns, the forming of geometrical solids in cardboard, and the use of tools and instruments," which are in use in some foreign schools, and are found to be "not without a useful reflex influence on all the ordinary school studies." The inspector is to report on the working of any system of manual in struction which may be adopted, though "no special grant is made by this Department." The words we have italicized clearly tend to confirm our impression as to the intention of the Science and Art Department to include manual instruction in their next Directory.

It is rather strange that under the head of "drawing" no reference is made to the change by which in future drawing will be made compulsory in boys' schools and optional in infant departments. It is true that drawing in ordinary schools will, as now, be paid for by the Science and Art Department, but power is given by the new Code to Her Majesty's Inspector to exempt schools from the necessity of taking the subject where the means of teaching it cannot be procured. We should like to know what standard the inspector will adopt in using this dispensing power. Will the standard be the same in all districts?

This is the question to which we return again and again after examining in detail the various changes in the Code and the instructions. All will depend on the inspectors. What will their action be? We agree on the whole in the praise accorded in the instructions to the "ability, discretion, and fairness with which Her Majesty's Inspectors discharge their arduous duties," but nevertheless, in particular cases, complaints of their action have not been wanting. The inspectors have hitherto been burdened with an amount of routine work which has to some extent hindered them from forming a really intelligent estimate of the value of the school work which they have to assess. This burden is now lightened, more visits may be paid without notice, and thus more intimate knowledge may be acquired of the real work of the school. "It will be 
largely owing," we read, " to your influence if all who are concerned with the management of schools habitually regard the officers of this Department not merely as critics and examiners, but as advisers and helpers, in the performance of an important public work." That is the ideal to aim at, though there is a good deal of lee-way to make up before it is realized.

\section{ORANGES IN INDIA.}

The Cultivated Oranges and Lemons of India and Ceylon. By E. Bonavia, M.D. Pp. 384, with an Atlas of 259 Plates 7 inches long by 9 inches broad. (London: W. H. Allen, 1890.)

FO OR twenty years past Dr. Bonavia has been distinguished in India as a horticulturist. He has been in charge of the Horticultural Gardens at Lucknow, where he has conducted many valuable experiments. Of late years he has tricd oranges, and he has also collected information concerning oranges from various parts of India. India, taken as a whole, is very poorly supplied with fruit ; really good mangoes and litchis are nearly everywhere dear, and remain in season but a short time. Oranges in several parts of India are cheap and excellent; improvement in their cultivation and extension in their circulation are matters of importance. The book of Dr. Bonavia contains his own experiences and notes, which are valuable. His second-hand information, which he has collected in the fashion of an Indian Secretary to Government or Minister of Agriculture, is of very small value, but is certainly superior to many secretarial compilations about hemp, jute, cotton, \&c.

The first ninety pages treat of the various groups of oranges, lemons, limes, citrons, \&c., with their subvarieties; the next fifty pages treat of their cultivation in India; fifteen pages treat of their uses; eleven of the orange trade in. India; twenty-one of the morphology of Citrus ; forty of the origin of the Citrus and the derivation of its Indian names. Then follow I20 pages of appendix, containing a miscellaneous collection of "cuttings" relating in some way to the subjects in the book, with a translation of the chapters relating to Citrus in Rumphius's "Herbarium Amboinense." The greater part of this appendix appears of small importance; while Dr. Bonavia has by no means exhausted what first-rate authorities have written regarding oranges. The atlas of plates gives hardly anything but outline drawings of oranges and their leaves; a very small selection of these would have served every useful purpose.

Dr. Bonavia has summed up for us the conclusions of his book under seven heads (p. 245) :-

(a) The pummelo (Citrus decumana, Willd.), is not specifically separable from the orange (C. Aurantium, Linn.).-This is a point of no possible importance, when naturalists know no line between a well-marked variety and a dubious "species" ; but Lowe ("Fl. Madeira," p. 73) agrees with Dr. Bonavia.

(b) The sweet orange of Europe (C. Aurantium, Linn.) is a distinct race from the Mandarin orange (C. nobilis, Lour.).--This is correct, and well brought out by Dr. Bonavia ; but it is also done very clearly by Lowe (" Fl. Madeira" [1857], pp. 73, 74). (c) The India name "suntara," for C. nobilis, is not a corruption merely of Cintra.

(d) The European words "lime," "lemon," are probably derived from Malay words.

(e) Huge forms of Citrus fruit may have risen from a fusion of two ovaries [p. 187, "My view would require that the Citrus fruit should have originated in two whorls of carpels, the outer or rind-whorl and the inner or pulp-whorl"].

( $f$ ) The true lime (C. acida, Roxb.) has more probably descended from $C$. hystrix, Kurz, than from $C$. medica, Linn.

$(g)$ The juice-vesicles of the Citrus pulp are probably homologous with the oil-cells of the rind and leaves, and perhaps with the ovules.

It will be best to reverently draw a veil over the conclusions $(e)$ and $(g)$ and over the whole chapter on morphology. And the other five "conclusions," except (b), do not conclude anything. The foregoing is Dr. Bonavia's own summary of what he has proved, but he has done more than he claims ; his account of his own horticultural observations is of value, and his deductions very generally correct. Of these only a few can be given here.

(1) The Khatta or Karna orange of Upper India produces two kinds of fruit on the same tree and on the same branch, viz. (I) the regular crop, of smooth oranges, ripe at the end of the dry season, and (2) the after crop, of grossly-warted oranges, ripe at the beginning of the rains.

(2) The European orange (C. Aurantium) is only known in India as a cultivated foreign orange, and is not common. It has been probably introduced into India in modern times-possibly from the West.

(3) The $C$. nobilis is the sweet orange of India ; it has been in India from ancient times, and is possibly indigenous on the north-east frontier. It has only been brought to Europe in modern times. The Tangerine orange is a small form of it. (This C. nobilis is a more slender tree than $C$. Aurantium; its oranges are depressed at the poles; the rind is very full of large oilglands, and separates easily from the pulp, which lies more or less loosely in the rind as in a bag.)

(4) The pummelo (i.e. Pompel-moes) of India and Ceylon is in flavour, structure of carpels, colour of pulp, \&c., very distinct from the Syrian shaddock, i.e. the shaddock of English fruit-shops.

(5) In the plains of Upper India (Delhi, Lucknow, \&c.) the Indian orange ( $C$. nobilis) can be successfully cultivated, but requires irrigation (well-water being better than canal-water), budding, trenching, shade, special preparation of the soil by lime or manure, \&c.

Every page of Dr. Bonavia's book offers opportunity of comment: the remaining space here available is devoted to the practical subject of the Indian sweet orange, C. nobilis, which we shall call the "Mandarin," and, for shortness, state first our own beliefs concerning it.

There are (according to Dr. Bonavia) three great centres of cultivation of the "suntara" in India, viz. ( $\mathrm{I}$ ) Sylhet, i.e. South Khasia ; (2) Central India ; (3) Delhi and Oudh. From Khasia (fide Bonavia) about 4000 tons, worth $£ 4$ a ton, are exported to Bengal, mainly to Calcutta. From Central India about 800 tons go by rail 